\title{
Lutein protects against ischemia/reperfusion injury in rat kidneys
}

\author{
ZHEN-GUO LIU, ZONG-CAI QI, WEI-LIANG LIU and WEI-ZHI WANG \\ Department of Anesthesiology, Weifang People's Hospital, Weifang, Shandong 261041, P.R. China \\ Received February 23, 2014; Accepted October 6, 2014
}

DOI: $10.3892 / \mathrm{mmr} .2014 .2982$

\begin{abstract}
Ischemia-reperfusion (I/R) injury has a major impact on renal dysfunction during transplantation. The present study investigated the role of lutein against I/R injury-induced oxidative stress in rat kidneys. Biochemical analysis and oxidative stress parameters demonstrated that lutein protected the rat kidney significantly from I/R injury. Pretreatment with lutein significantly increased the total antioxidant capacity with a concomitant decline in the total oxidant status. Rats with I/R injury showed a significant increase in oxidative stress. The results revealed significant increases in the levels of lipid peroxidation and protein carbonyl content with concomitant decreases in enzymic and non-enzymic antioxidants. The activity of these enzymes was reversed and demonstrated a significant increase following lutein pre-treatment compared with the rats subjected to I/R injury alone. Furthermore, lutein protected the renal tissue from $\mathrm{I} / \mathrm{R}$ injury by maintaining normal kidney architecture and led to a reduction in the levels of the renal markers urea and creatinine in the serum. These results demonstrated clear evidence that lutein offered a significant protective effect against I/R injury by enhancing antioxidant defense mechanisms.
\end{abstract}

\section{Introduction}

The major reason for acute renal failure following renal transplantation has been implicated to be due to renal ischemia-reperfusion $(I / R)$ injury $(1,2)$. A limitation in oxygen supply causes I/R injury, which ultimately results in the perturbation of normal cellular processes (3). Ischemia primarily affects cellular function through the release of reactive oxygen species (ROS) and the pathophysiology of I/R leads to cell death via apoptosis/necrosis through oxidative stress and inflammatory mediators. There is clear evidence that oxidative stress acts as a major contributor to renal I/R injury (4-6). However, these stress conditions can be prevented or protected

Correspondence to: Dr Wei-Liang Liu, Department of Anesthesiology, Weifang People's Hospital, 151 Guangwen Street, Weifang, Shandong 261041, P.R. China

E-mail: 15806368556@126.com

Key words: ischemia, oxidative stress, lutein, antioxidants, renal ischemia/reperfusion injury from using an appropriate pharmacological approach, which causes a complete reduction in the oxidative stress status. Previous studies have reported the positive role of nitric oxide, leptin, antioxidants and glutamine supplementation in protective intervention prior to ischemia $(5,7)$.

Lutein, a non-vitamin A carotenoid is a member of the xanthophyll group, which can be obtained through the diet by consuming various dark green leafy vegetables and fruits (8-10). The hydroxyl group in the lutein structure reacts strongly with ROS, acting as an efficient free radical scavenger and imparting various health benefits (11). Several studies have suggested that lutein exerts its biological properties through its antioxidant property and by reducing oxidative stress responses (12-15). Lutein has been demonstrated to possess pharmacological activities as an anti-inflammatory (12) and anticancer agent (13), and provides protection against gastric lesions (14) and gastrointestinal ulcers (15).

The aim of the present study was to investigate the protective role of lutein against renal I/R injury in the context of oxidative stress and inflammatory responses.

\section{Materials and methods}

Animals. The study was approved by the institutional animal care and use committee in the Department of Anesthesiology, (Weifang People's Hospital, Weifang, China). Male Wistar rats (n=24; weight, 150-200 g; age, 8-10 weeks; Animal House Facility, Weifang Medical University) were used for the present study. The rats were maintained under controlled conditions of $\left(21 \pm 2^{\circ} \mathrm{C}\right)$ and relative humidity $(70 \%)$ with an alternating dark and light cycle. The animals were fed with commercially available rat pellets and water ad libitum. Following acclimatization, the animals were randomly divided into five groups, with six rats per group.

Study design. The five groups of rats, which were examined in the present study received different treatments, as follows: Group I (control), no surgery or treatment was administered; group II (sham), sham surgery was performed with exposure of the renal pedicles but without I/R; group III (lutein), lutein was administered through intraperitoneal injection at a dose of $0.2 \mathrm{mg} / \mathrm{kg}$ consecutively for 7 days; group IV (I/R), the animals were subjected to $45 \mathrm{~min}$ bilateral ischemia followed by $24 \mathrm{~h}$ reperfusion; and group V (lutein+I/R), lutein was administered through intraperitoneal injection at a dose of $0.2 \mathrm{mg} / \mathrm{kg}$ consecutively for 7 days and subjected to $45 \mathrm{~min}$ bilateral ischemia followed by $24 \mathrm{~h}$ reperfusion. 
Following a $12 \mathrm{~h}$ fasting period, the animals were then anesthetized with xylazine $(10 \mathrm{mg} / \mathrm{kg})$ and ketamine (70 mg/kg). A body temperature of $37.5^{\circ} \mathrm{C}$ was maintained throughout the experimental procedure using a heating lamp. Prior to kidney isolation, the abdominal region was sterilized with povidone iodine solution. A midline minimal incision was made to the abdomen and the two kidneys were isolated. The abdomen was closed without any further procedure in the sham group. The sutures used in the study were obtained from Kent scientific corporation (Torrington, CT, USA). In the I/R and lutein+I/R groups, non traumatic microvascular clamps (S\&T microvascular clamps, Neuhasen, Switzerland) were used to occlude the renal arteries for $45 \mathrm{~min}$. The clamps were then removed and the kidney was inspected for restoration of blood flow prior to closure of the incision. Saline $\left(5 \mathrm{ml}\right.$ at $\left.37^{\circ} \mathrm{C}\right)$ was administered intraperitoneally to prevent fluid loss prior to abdominal closure of the rats. Following completion of $24 \mathrm{~h}$ renal reperfusion, the animals were re-anesthetized with xylazine $(10 \mathrm{mg} / \mathrm{kg})$ and ketamine (70 mg/kg; (both from Sigma-Aldrich, St. Louis, MO, USA), and the abdomen was reopened. Blood was collected by cardiac puncture, which was immediately centrifuged at $1,000 \times \mathrm{g}$ and the isolated serum was stored at $-70^{\circ} \mathrm{C}$ until subsequent analysis. Bilateral nephrectomies were performed and the left kidney was stored for histopathological analysis in $10 \%$ formalin solution. The right kidney was stored at $-70^{\circ} \mathrm{C}$ and was used for all the subsequent biochemical assays.

Histopathological analysis. The kidneys from the rats were fixed with $10 \%$ formaldehyde, dehydrated in graded alcohol and embedded in paraffin. Sections $(5 \mu \mathrm{m})$ were cut from the tissues using a microtome and mounted onto glass slides. The slides were counterstained with hematoxylin \& eosin and analyzed for histological changes using an inverted microscope (CKX31; Carl Zeiss, Oberkochen, Germany).

Assessment of renal function. Renal function was determined by measurement of the serum urea (16) and serum creatinine levels (17).

Estimation of serum total antioxidant capacity (TAC). The TAC of the serum was determined, as described by Erel (18). The assay principle involves the reaction between antioxidants in the sample and free radicals in the reaction mixture to form the hydroxyl radical, which was measured spetrophometrically at $444 \mathrm{~nm}$. The results are expressed as mmol of Trolox equivalent/1.

Total oxidant status (TOS) of the serum. The TOS of the serum was determined, as described by Erel (19). The results are expressed as $\mu \mathrm{mol} \mathrm{H}_{2} \mathrm{O}_{2}$ equivalent/l. The principle is based on the oxidation of the ferrous ion-o-dianisidine complex to ferric ion by the oxidants present in the sample. The formation of a colored complex in the presence of xylenol orange in an acidic medium was measured spectrophotometrically (Beckman Instruments, Brea, CA, USA). The absorbance was proportional to the quantity of oxidant molecules present in the sample and the quantity of oxidants in the sample was compared with that of $\mathrm{H}_{2} \mathrm{O}_{2}$. The results were expressed as $\mu$ mol $\mathrm{H}_{2} \mathrm{O}_{2}$ equivalent/l.
Determination of oxidative stress and antioxidant status. The tissues were homogenized using an Ultra-Turrax T 25 Basic dispersing instrument, IKA, Staufen, Germany) using ice-cold Tris- $\mathrm{HCl}$ buffer $(50 \mathrm{mM}$; $\mathrm{pH} 7.4)$ at $4^{\circ} \mathrm{C}$. Following homogenization, the homogenate was centrifuged at $600 \mathrm{x} \mathrm{g}$ for $15 \mathrm{~min}$ and the supernatant was isolated. The resultant $5 \mathrm{ml}$ of supernatant was aliquoted as $500 \mu \mathrm{l}$ in each tube, stored at $-20^{\circ} \mathrm{C}$ and used for the oxidative stress parameters. Protein estimation was then performed, as described previously (20).

\section{Antioxidant enzyme activity}

Total $\mathrm{Cu}-\mathrm{Zn}$ and $\mathrm{Mn}$ superoxide dismutase (SOD) activity. The assay to determine SOD activity was performed in the ethanol phase of the sample; the ethanol phase was obtained by adding $1.0 \mathrm{ml}$ ethanol-chloroform mixture (5:3, $\mathrm{v} / \mathrm{v}$ ) to an equal volume of the sample. The SOD activity was determined based on a nitroblue tetrazolium (NBT) reduction (21). SOD activity (1 unit) = quantity required for $50 \%$ inhibition of NBT reduction. SOD activity was expressed as $\mathrm{U} / \mathrm{mg}$ protein.

Glutathione peroxidase (GPx) activity. The activity of GPx was determined using a method previously described by Paglia and Valentine (22), in which oxidized glutathione is reduced by glutathione reductase and NADPH and the oxidation of NADPH to $\mathrm{NADP}^{+}$was measured by a decrease in absorbance at $340 \mathrm{~nm}$. The GPx activity was expressed as $\mathrm{U} / \mathrm{mg}$ protein.

Catalase (CAT) activity. The activity of CAT was determined according to the method described by Aebi (23). The reaction mixture contained the tissue sample in $30 \mathrm{mM} \mathrm{H}_{2} \mathrm{O}_{2}$ and $50 \mathrm{mM}$ phosphate buffer ( $\mathrm{pH}$ 7.0). The activity of CAT was then estimated by the decrease in the absorbance of $\mathrm{H}_{2} \mathrm{O}_{2}$ at $240 \mathrm{~nm}$.

Glutathione (GSH) content. The homogenate was resuspended in 5\% meta-phosphoric acid and the supernatant was collected for determination of total GSH using a GSH assay kit (Trevigen Inc., Gaithersburg, MD, USA). The GSH levels were expressed as nmol/mg protein.

Estimation of tissue protein carbonyl content (PCC). The carbonyl contents formed during the reaction between the carbonyl group and 2,4-dinitrophenylhydrazine to form 2,4-dinitrophenylhydrazone was measured spectrophometrically (24). The results were expressed as carbonyl (nM)/mg protein.

Estimation of lipid peroxidation. The levels of thiobarbituric acid (TBA) reactive substances were determined, as described previously (25). The reaction is based on the reaction of malondialdehyde (MDA) with TBA. The pink color formed was measured at $532 \mathrm{~nm}$ using a spectrophotometer. The results were expressed as TBA reactants formed $(\mathrm{nmol}) / \mathrm{g}$ wet tissue.

Statistical analysis. The data were analyzed using one-way analysis of variance followed by Tukey's multiple comparison test using SPPS software, version 22.0 (SPSS, Inc., Chicago, IL, USA). $\mathrm{P}<0.01$ was considered to indicate a statistically 
Table I. Effect of lutein on TAC and TOS.

\begin{tabular}{lrrrr}
\hline Parameter & Group I & Group II & Group III & Group IV \\
\hline TAC & $4.2 \pm 0.02$ & $4.0 \pm 0.02^{\mathrm{a}}$ & $4.2 \pm 0.01^{\mathrm{a}}$ & $2.8 \pm 0.01^{\mathrm{b}}$ \\
TOS & $21 \pm 1.12$ & $22 \pm 1.34^{\mathrm{a}}$ & $20 \pm 1.04^{\mathrm{a}}$ & $2.5 \pm 0.01^{\mathrm{c}}$ \\
\hline
\end{tabular}

Group I, control; Group II, sham; Group III, lutein; Group IV, I/R; and Group V, lutein+I/R. Results are expressed as the mean \pm standard error of the mean ( $\mathrm{n}=6$ in each group). ${ }^{\mathrm{a} N o t}$ significant compared with the control. ${ }^{\mathrm{b}} \mathrm{P}<0.001$, compared with the control. ${ }^{\mathrm{c}} \mathrm{P}<0.001$ compared with the I/R group. Data were analyzed using one-way analysis of variance followed by Tukey's multiple comparison test. I/R, ischemia-reperfusion; TAC, total antioxidant capacity; TOS, total oxidant status.

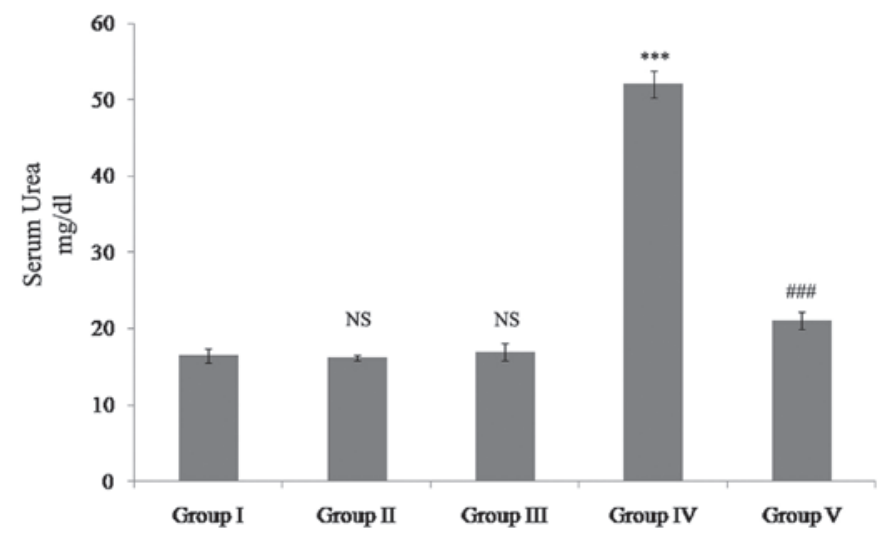

Figure 1. Effect of lutein on serum urea in Wistar rats. Group I, control; Group II, sham; Group III, lutein; Group IV, I/R; and Group V, lutein+I/R. Results are expressed as the mean \pm standard error of the mean $(n=6$ in each group). ${ }^{* * * *} \mathrm{P}<0.001$, compared with the control. ${ }^{\# \#} \mathrm{P}<0.001$ compared with the I/R group. NS, not significant compared with the control. Data were analyzed using one-way analysis of variance followed by Tukey's multiple comparison test. I/R, ischemia-reperfusion.

significant difference. All biochemical experiments were performed in triplicate to ensure reproducibility.

\section{Results}

Effect of lutein on renal function in rats exposed to I/R injury. The present study determined the renal function by estimating the levels of the kidney markers serum urea and creatinine. A significant increase in serum urea and creatinine levels $(\mathrm{P}<0.001)$ was observed in the rats subjected to $\mathrm{I} / \mathrm{R}$ injury compared with the control rats. Pretreatment with lutein followed by I/R injury significantly decreased the levels of the two markers $(\mathrm{P}<0.001)$ compared with the group treated with I/R alone. No significant differences were observed in the rats treated with sham and lutein compared with the control group (Figs. 1 and 2). Histopathological observations revealed that $I / R$ caused significant damage to the renal tubules and glomeruli with inflammatory infiltration. The control and lutein-treated rats maintained a normal kidney morphology and pretreatment with lutein also maintained the normal renal tissue morphology (Fig. 3).

Effect of lutein on total antioxidant capacity (TAC) and total oxidant status (TOS). As Table I shows, a significant increase $(\mathrm{P}<0.001)$ in TOS and a significant decrease $(\mathrm{P}<0.001)$ in TAC were observed in the I/R-treated rats compared with the

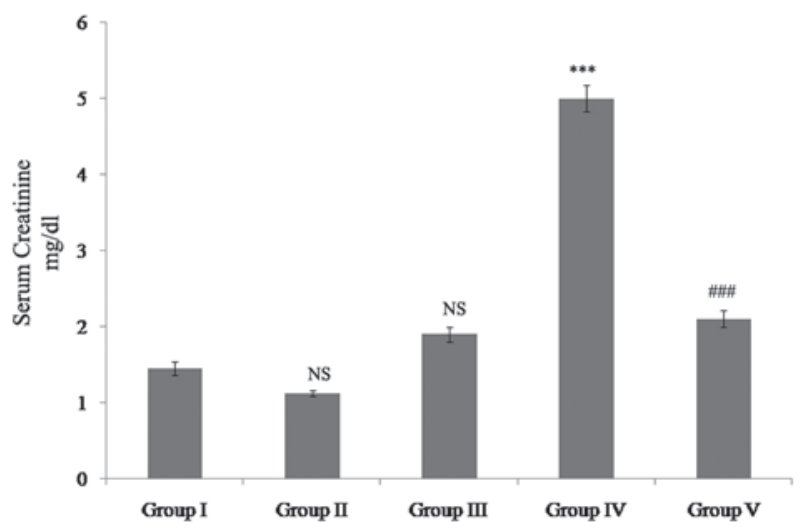

Figure 2. Effect of lutein on levels of serum creatinine in Wistar rats. Group I, control; Group II, sham; Group III, lutein; Group IV, I/R; Group V, lutein $+\mathrm{I} / \mathrm{R}$. Results are expressed as the mean \pm standard error of the mean ( $\mathrm{n}=6$ in each group). ${ }^{* * *} \mathrm{P}<0.001$, compared with the control. ${ }^{\# \#} \mathrm{P}<0.001$ compared with the I/R group. NS, not significant compared with the control. Data were analyzed using one-way analysis of variance followed by Tukey's multiple comparison test. I/R, ischemia-reperfusion.

control group. Treatment with lutein followed by I/R treatment led to a statistically significant decrease $(\mathrm{P}<0.001)$ in TOS with a significant increase $(\mathrm{P}<0.001)$ in TAC compared with the I/R-treated group. However, no significant difference was observed in the rats treated with lutein and the sham group compared with the control group.

Effect of lutein on lipid peroxidation and PCC content. A significant increase in the levels of lipid peroxides and PCC $(\mathrm{P}<0.001)$ was observed in the I/R-treated rats. No significant differences in the levels were observed in the rats treated with lutein and sham when compared with the control group. In the rats pretreated with lutein followed by I/R injury, significant decreases $(\mathrm{P}<0.001)$ in the levels of lipid peroxide and PCC were observed when compared with the levels of the I/R group (Figs. 4 and 5).

Protective effect of lutein on antioxidant status. The results of the present study demonstrated a significant decrease $(\mathrm{P}<0.001)$ in the levels of GSH, SOD, GPx and CAT $(\mathrm{P}<0.01)$ in the I/R-treated rats compared with the control group. Pre-treatment with lutein followed by I/R injury significantly increased the antioxidant status of SOD and GPx $(\mathrm{P}<0.001)$, and GSH and CAT $(\mathrm{P}<0.01)$ compared with the I/R-treated rats. No significant differences were observed in the rats treated with lutein alone compared with the control rats (Table II). 
Table II. Effect of lutein on enzymic and non-enzymic antioxidant status in renal tissue.

\begin{tabular}{lcrrrr}
\hline Parameter & Group I & Group II & Group III & Group IV & Group V \\
\hline GSH & $55 \pm 1.09$ & $52 \pm 1.20^{\mathrm{a}}$ & $51 \pm 1.18^{\mathrm{a}}$ & $23 \pm 1.17^{\mathrm{b}}$ & $41 \pm 1.14^{\mathrm{d}}$ \\
SOD & $112 \pm 2.10$ & $115 \pm 1.90^{\mathrm{a}}$ & $112 \pm 1.54^{\mathrm{a}}$ & $54 \pm 1.70^{\mathrm{b}}$ & $92 \pm 1.60^{\mathrm{e}}$ \\
CAT & $0.09 \pm 0.001$ & $0.082 \pm 0.001^{\mathrm{a}}$ & $0.086 \pm 0.003^{\mathrm{a}}$ & $0.01 \pm 0.002^{\mathrm{c}}$ & $0.06 \pm 0.002^{\mathrm{d}}$ \\
GPx & $0.90 \pm 0.001$ & $0.96 \pm 0.001^{\mathrm{a}}$ & $0.92 \pm 0.004^{\mathrm{a}}$ & $0.29 \pm 0.001^{\mathrm{b}}$ & $0.76 \pm 0.001^{\mathrm{e}}$ \\
\hline
\end{tabular}

Group I, control; Group II, sham; Group III, lutein; Group IV, I/R; and Group V, lutein+I/R. Results are expressed as the mean \pm standard error of the mean ( $\mathrm{n}=6$ in each group). ${ }^{\mathrm{a}}$ Not significant compared with the control. ${ }^{\mathrm{b}} \mathrm{P}<0.001$ and ${ }^{\mathrm{c}} \mathrm{P}<0.01$, compared with the control. ${ }^{\mathrm{d}} \mathrm{P}<0.05$ and ${ }^{\mathrm{e}} \mathrm{P}<0.001$, compared with the I/R group. Data were analyzed using one-way analysis of variance followed by Tukey's multiple comparison test. GSH in nM GSH/g tissue, SOD, CAT and GPx activities in U/mg protein. I/R, ischemia-reperfusion; GSH, glutathione; SOD, superoxide dismutase; CAT, catalase; Gpx, glutathione peroxidase.
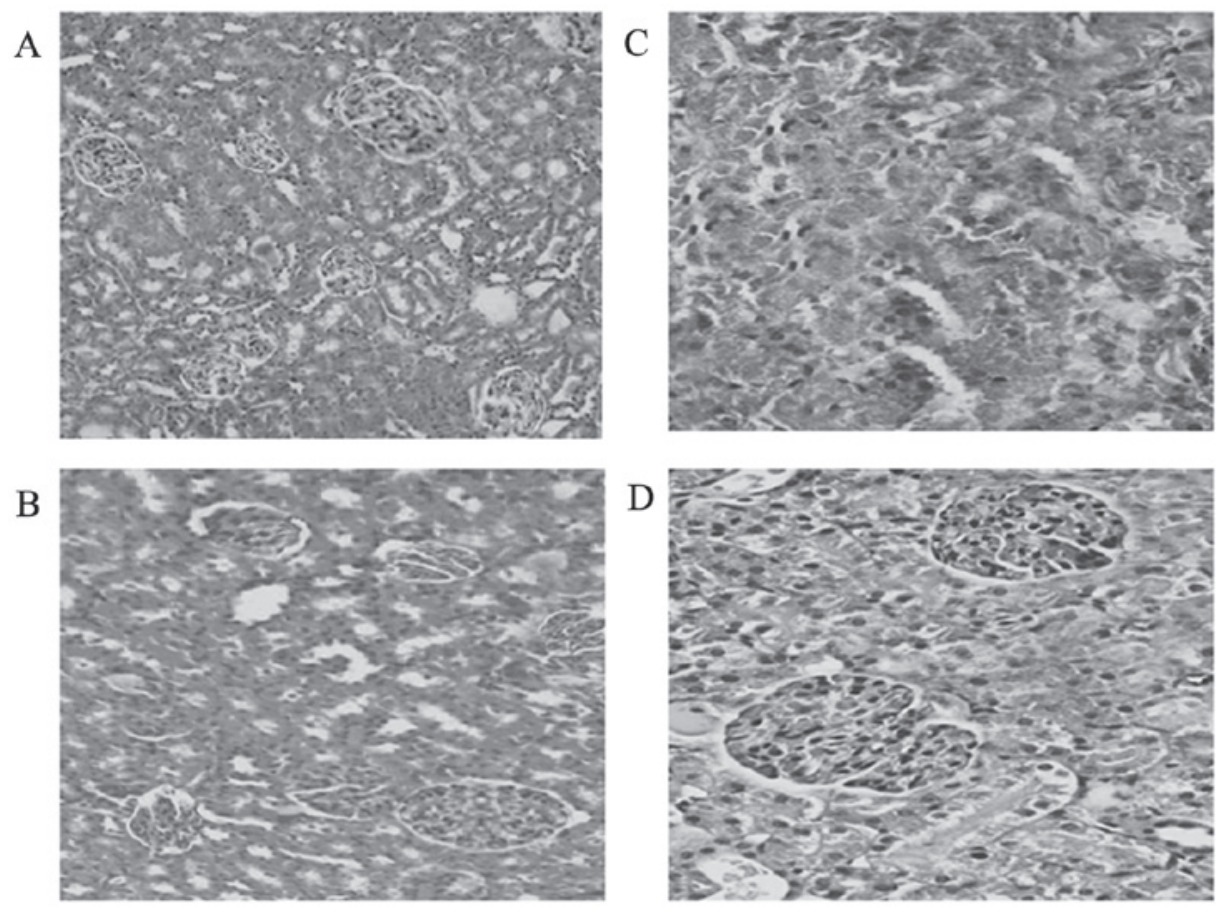

Figure 3. Histopathological effects of lutein treatment following I/R injury (hematoxylin and eosin; magnification, $\mathrm{x} 400$ ). (A) Control. (B) Lutein, normal renal morphology. (C) Renal I/R injury; distinctive damage to renal tissue. (D) Lutein+I/R, normal renal architecture. I/R, ischemia-reperfusion.

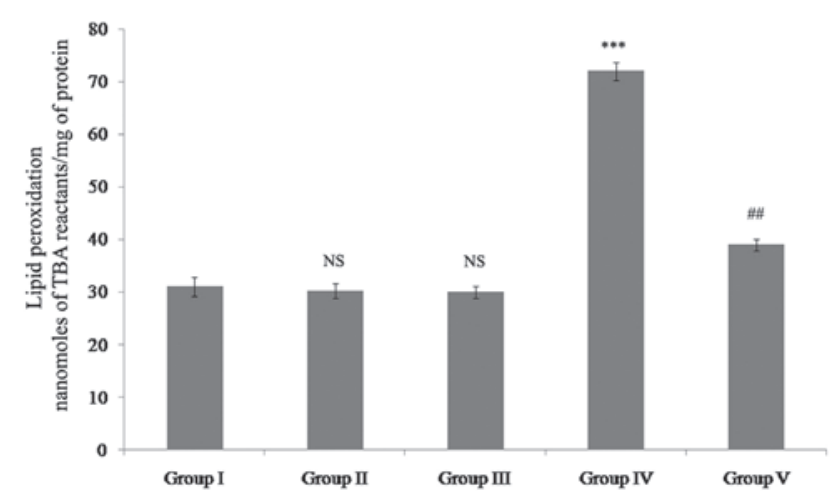

Figure 4. Effect of lutein on levels of TBA. Group I, control; Group II, sham; Group III, lutein; Group IV, I/R; Group V, lutein+I/R. Results are expressed as the mean \pm standard error of the mean ( $\mathrm{n}=6$ in each group). $\mathrm{P}<0.001$ compared with the control. ${ }^{\# /} \mathrm{P}<0.01$ compared with the I/R group. NS, not significant compared with the control. Data were analyzed using one-way analysis of variance followed by Tukey's multiple comparison test. I/R, ischemia-reperfusion; TBA, thiobarbituric acid.

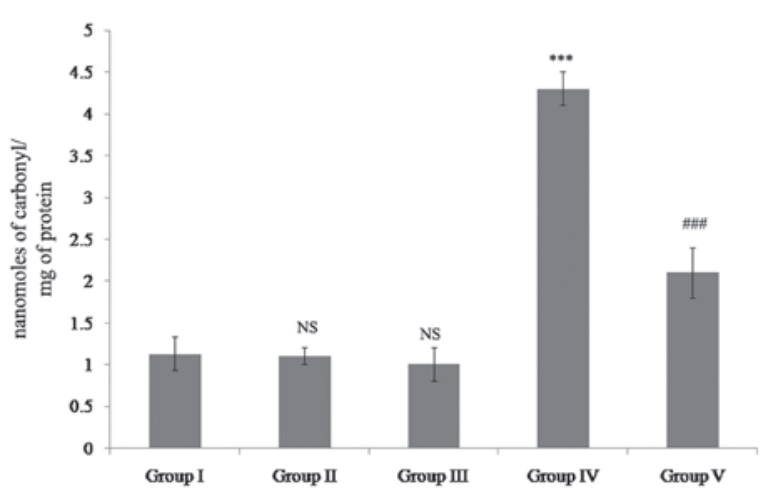

Figure 5. Effect of lutein on protein carbonyl content. Group I, control; Group II, sham; Group III, lutein; Group IV, I/R; Group V, lutein+I/R. Results are expressed as the mean \pm standard error of the mean $(n=6$ in each group). ${ }^{* * *} \mathrm{P}<0.001$ compared with the control. ${ }^{\# \#} \mathrm{P}<0.01$ compared with the I/R group. NS, not significant compared with the control. Data were analyzed using one-way analysis of variance followed by Tukey's multiple comparison test. I/R, ischemia-reperfusion. 


\section{Discussion}

It has been well documented that the oxidative stress induced during I/R injury is important in acute and chronic renal dysfunction $(26,27)$. Oxidative stress is a condition in which the levels of oxidants are increased compared with those of the antioxidant levels inside the cells and determination of the levels of oxidants and antioxidants demonstrates a state of oxidant imbalance during specific conditions (28). The present study demonstrated a significant increase in the TOS and a significant decrease in the TAC of rats subjected to I/R injury. Lutein pretreatment followed by $\mathrm{I} / \mathrm{R}$ revealed higher levels of antioxidants compared with oxidants.

The ROS generated during oxidative stress can initiate a chain of reactions affecting cellular biomolecules, including DNA, protein and lipids (29). Previous studies have demonstrated a significant increase in levels of lipid peroxidation during I/R injury (30-32). Normally, the cells contain various enzymic and non-enzymic antioxidant enzymes, including GSH, SOD, CAT and GPx. These endogenous enzymes counteract the oxidative stress conditions by scavenging ROS through combined defense mechanisms. SOD catalyzes superoxide $(\mathrm{O} 2 \bullet-)$ and hydroxyl ions $(\mathrm{OH} \bullet-)$ to form $\mathrm{H}_{2} \mathrm{O}_{2}$. These $\mathrm{H}_{2} \mathrm{O}_{2}$ molecules are further decomposed by catalase into water and oxygen (33). GSH is an important non-protein thiol, which acts as a first defense against oxidative stress (34). In addition, the conjugation of GSH and GPx offers protective effects by quenching the free radicals (35). In the present study, significant increases in the levels of MDA and PCC, and a significant decrease in the antioxidant status in the kidney were observed following I/R injury compared with the control group, which demonstrated that imbalance in the oxidant-antioxidant status was a major factor in I/R injury. However, these conditions were significantly reversed by lutein through a significant decrease in the levels of MDA and PCC and a concomitant increase in enzymic and non-enzymic antioxidants. The results of the present study demonstrating neutralization of the oxidative imbalance were attributed to the antioxidant potential of lutein. Lutein, a member of the xantophyll family, protects against macular damage and age-related macular degeneration through its antioxidant properties (36-38). In addition, similar effects of lutein have been observed in reducing oxidative stress in retinal I/R injury by enhancing antioxidative defense mechanisms (39).

Oxidative stress and the subsequent effects of downstream mediators are often implicated in cellular dysfunction (6). Therefore, the present study evaluated renal function through the kidney specific markers, serum urea and creatinine. The significant increases observed in these kidney markers following I/R injury were ameliorated by treatment with lutein. These effects may be due to the antioxidant properties and cytoprotective effect of lutein neutralizing oxidative stress. In addition, histological examination revealed tubular damage with necrosis and inflammatory infiltration in rats subjected to I/R injury. Conversely, pretreatment with lutein led to complete protection against I/R injury, which was evident by the preservation of normal kidney architecture. Similar protective effects of lutein, in maintaining kidney markers and cellular architecture, have been observed against cisplatin-induced acute renal failure (40).
In conclusion, the results of the present study demonstrated the protective effect of lutein against kidney I/R injury through a reduction in renal dysfunction. Lutein provided significant protection by reversing the oxidative stress through the enhancement of antioxidant defense mechanisms. The protective effect against I/R injury may be attributed to the ability of lutein to act as a potent free radical scavenger, to enhance antioxidant status and to maintain kidney architecture. The present study demonstrated that lutein can be used as a potential pharmacophore in preventing $I / R$ injury in the rat kidney. However, further studies are required to identify the precise molecular mechanism underlying the action of lutein in order for it to be used in therapy to prevent I/R injury.

\section{References}

1. Xue JL, Daniels F, Star RA, Kimmel PL, Eggers PW, Molitoris BA, Himmelfarb J and Collins AJ: Incidence and mortality of acute renal failure in Medicare beneficiaries to 2001. J Am Soc Nephrol 17: 1135-1142, 2006.

2. Gueler F, Gwinner W, Schwarz A and Haller H: Longterm effects of acute ischemia and reperfusion injury. Kidney Int 66: 523-527, 2004.

3. Le Dorze M, Legrand M, Payen D and Ince C: The role of the microcirculation in acute kidney injury. Curr Opin Crit Care 15: 503-508, 2009

4. Beckman JK, Yoshioka T, Knobel SM and Greene HL: Biphasic changes in phospholipid hydroperoxide levels during renal ischemia/reperfusion. Free Radic Biol Med 11: 335-340, 1991.

5. Mallick IH, Yang W, Winslet MC and Seifalian AM: Ischemia-reperfusion injury of the intestine and protective strategies against injury. Dig Dis Sci 49: 1359-1377, 2004.

6. Carden DL and Granger DN: Pathophysiology of ischaemia-reperfusion injury. J Pathol 190: 255-266, 2000.

7. Hacioglu A, Algin C, Pasaoglu O, Pasaoglu E and Kanbak G: Protective effect of leptin against ischemia-reperfusion injury in the rat small intestine. BMC Gastroenterol 5: 37, 2005.

8. Mangels AR, Holden JM, Beecher GR, Forman MR and Lanza E: Carotenoid content of fruits and vegetables: an evaluation of analytic data. J Am Diet Assoc 93: 284-296, 1993.

9. Sommerburg O, Keunen JE, Bird AC and van Kuijk FJ: Fruits and vegetables that are sources for lutein and zeaxanthin: the macular pigment in human eyes. Br J Ophthalmol 82: 907-910, 1998.

10. Krinsky NI, Landrum JT and Bone RA: Biologic mechanisms of the protective role of lutein and zeaxanthin in the eye. Annu Rev Nutr 23: 171-201, 2003.

11. Ojima F, Sakamoto H, Ishiguro Y and Terao J: Consumption of carotenoids in photosensitized oxidation of human plasma and plasma low-density lipoprotein. Free Radic Biol Med 15: 377-384, 1993.

12. Krishnaswamy R, Devaraj SN and Padma VV: Lutein protects HT-29 cells against deoxynivalenol-induced oxidative stress and apoptosis: prevention of NF-kappa B nuclear localization and down regulation of NF-kappa $\mathrm{B}$ and cyclo-oxygenase-2 expression. Free Radic Biol Med 49: 50-60, 2010.

13. Chucair AJ, Rotstein NP, Sangiovanni JP, During A, Chew EY and Politi LE: Lutein and zeaxanthin protect photoreceptors from apoptosis induced by oxidative stress: relation with docosahexaenoic acid. Invest Ophthalmol Vis Sci 48: 5168-5177, 2007.

14. Jávor T, Bata M, Lovász L, Morón F, Nagy L, Patty I, Szabolcs J, Tárnok F, Tóth G and Mózsik G: Gastric cytoprotective effects of vitamin A and other carotenoids. Int J Tissue React 5: 289-296, 1983.

15. Mozsik G, Bódis B, Figler M, Király A, Karádi O, Pár A, Rumi G, Süo G, Tóth G and Vincze A: Mechanisms of action of retinoids in gastrointestinal mucosal protection in animals, human healthy subjects and patients. Life Sci 69: 103-3112, 2001.

16. Natelson S, Scott ML and Beffa C: A rapid method for the estimation of urea in biological fluids. Am J Clin Pathol 21: 275-281, 1951.

17. Broad J and Sirota JH: Clearance of endogenous creatine in man. J Clin Invest 27: 645-654, 1948. 
18. Erel O: A novel automated method to measure total antioxidant response against potent free radical reactions. Clin Biochem 37: $112-219,2004$

19. Erel O: A new automated colorimetric method for measuring total oxidant status. Clin Biochem 38: 1103-1111, 2005.

20. Lowry OH, Rosenbrough NJ, Farr AL and Randall RJ: Protein measurement with the Folin phenol reagent. J Biol Chem 193: 265-275, 1951

21. Sun Y, Oberley LW and Li Y: A simple method for clinical assay of superoxide dismutase. Clin Chem 34: 497-500, 1988.

22. Paglia DE and Valentine WN: Studies on the quantitative and qualitative characterisation of erythrocyte glutathione peroxidase. J Lab Clin Med 70: 158-169, 1967.

23. Aebi H: Catalase In: Methods of enzymatic analysis. Bergmeyer U (ed). Academic Press, New York, pp673-677, 1974.

24. Levine RL, Garland D, Oliver CN, Amici A, Climent I, Lenz AG, Ahn BW, Shaltiel S and Stantman ER: Determination of carbonyl content in oxidatively modified proteins. In Methods in enzymology V 186, oxygen radicals in biological systems. Packer L and Glazer AN (eds). Academic Press, New York, pp464-478, 1990.

25. Esterbauer $\mathrm{H}$ and Cheeseman KH: Determination of aldehydic lipid peroxidation products: malonaldehyde and 4-hydroxynonenal. In: Oxygen radicals in biological systems, methods in enzymology. Packer L, Glazer AN (eds). Academic Pres, California, pp407-421, 1990.

26. Bonventre JV and Weinberg JM: Recent advances in the pathophysiology of ischemic acute renal failure. J Am Soc Nephrol 14: 2199-2210, 2003.

27. Weight SC, Bell PR and Nicholson ML: Renal ischemia - reperfusion injury. Br J Surg 83: 162-170, 1996.

28. Cristóvão C, Cristóvão L, Nogueira F and Bicho M: Evaluation of the oxidant and antioxidant balance in the pathogenesis of chronic obstructive pulmonary disease. Rev Port Pneumol 19: $70-5,2013$

29. Katz D, Mazor D, Dvilansky A and Meyerstein N: Effect of radiation on red cell membrane and intra cellular oxidative defense system. Free Radic Res 24: 199-204, 1996.
30. Irmak MK, Koltuksuz U, Kutlu NO, Yağmurca M, Ozyurt H, Karaman A and Akyol O: The eVect of caVeic acid phenethyl ester on ischemia-reperfusion injury in comparison with alphatocopherol in rat kidneys. Urol Res 29: 190-193, 2001.

31. Turgut F, Bayrak O, Catal F, Bayrak R, Atmaca AF, K1oc A, Akbas A, Akcay A and Unal D: Antioxidant and protective effects of silymarin on ischemia and reperfusion injury in the kidney tissues of rats. Int Urol Nephrol 40: 453-460, 2008.

32. Yoon HY, Kang NI, Lee HK, Jang KY, Park JW and Park BH: Sulforaphane protects kidneys against ischemia-reperfusion injury through induction of the Nrf2-dependent phase 2 enzyme. Biochem Pharmaco 75: 2214-2223, 2008.

33. McCord JM: Oxygen-derived free radicals in postischemic tissue injury. N Engl J Med 312: 159-163, 1985.

34. Reed DJ: Glutathione: toxicological implications. Annu Rev Pharmacol Toxicol 30: 603-631, 1990.

35. Michiels $\mathrm{C}$, Raes $\mathrm{M}$, Toussaint $\mathrm{O}$ and Remacle J: Importance of Se-glutathione peroxidase, catalase and $\mathrm{Cu} / \mathrm{Zn}$-SOD for cell survival against oxidative stress. Free Rad Biol Med 17: 235-248, 1994.

36. Goldberg J, Flowerdew G, Smith E, Brody JA and Tso MO: Factors associated with age-related macular degeneration. An analysis of data from the first National Health and Nutrition Examination Survey. Am J Epidemiol 128: 700-710, 1988.

37. Seddon JM, Ajani UA, Sperduto RD, Hiller R, Blair N, Burton TC, Farber MD, Gragoudas ES, Haller J, et al: Dietary carotenoids, vitamins A, C, and E, and advanced age-related macular degeneration. Eye Disease Case-Control Study Group JAMA 272: 1413-1420, 1994

38. Ribaya-Mercado JD and Blumberg JB: Lutein and zeaxanthin and their potential roles in disease prevention. J Am Coll Nutr 23: 567S-587S, 2004.

39. Li SY, Fung FK, Fu ZJ, Wong D, Chan HH and Lo AC: Anti-inflammatory effects of lutein in retinal ischemic/hypoxic injury: in vivo and in vitro studies. Invest Ophthalmol Vis Sci 53: 5976-5984, 2012.

40. Sindhu ER and Kuttan R: Carotenoid lutein protects the kidney against cisplatin-induced acute renal failure. J Environ Pathol Toxicol Oncol 18, 32: 21-28, 2013. 